\title{
Un hijo sano del patriarcado. Feminicidio en la novela No me ignores de Nicolás Poblete*
}

\author{
A Healthy Child of Patriarchy. Femicide in the Novel No me ignores by Nicolás \\ Poblete
}

Ainhoa Vásquez Mejías

Facultad de Letras, Pontificia Universidad Católica de Chile. Correo electrónico: aovasque@uc.cl

Pareciera que, tanto en los medios como en la opinión pública, estamos acostumbrados a concebir la criminalidad como una desviación, enfermedad mental o bestialidad. La novela No me ignores (2010) del chileno Nicolás Poblete, no obstante, cuestiona esta idea planteando la posibilidad de que los asesinos sean sujetos con plena racionalidad, amparados por un sistema que se los permite. Desde la voz de un feminicida, Poblete reflexiona acerca del asesinato de mujeres, por razones de género, en el contexto de una sociedad patriarcal que justifica y propicia todo tipo de violencia contra las mujeres.

Palabras clave: feminicidio, animalidad, racionalidad, misoginia, crimen

It appears that both in the media and in public opinion, we are accustomed to conceive crime as a deviation, a mental illness or a bestiality. The novel No me ignores (2010), by Chilean author Nicolás Poblete, however, questions this idea raising the possibility that murderers are fully rational individuals protected by a system that allows this. From a femicide's voice, Poblete reflects on the murder of women for gender reasons in the context of a patriarchal society that justifies and promotes all forms of violence against women.

Keywords: femicide, animality, rationality, misogyny, crime

\section{INTRODUCCIÓN}

A menudo leemos en los titulares de los periódicos, escuchamos en los noticieros, referimos en conversaciones cotidianas, que un hombre asesino es un hombre enfermo, perturbado, psiquiátricamente inestable, un animal. Justificaciones que implican que esa persona asesina es diferente a nosotros, los racionales, los humanos sanos. El

Este artículo forma parte de mi tesis Voces del feminicidio: víctimas y victimarios en novelas y telenovelas chilenas recientes, con la que obtuve el grado de Doctora en Literatura por la Pontificia Universidad Católica de Chile. 
presente artículo propone que la novela No me ignores $(2010)^{1}$ del escritor chileno Nicolás Poblete, pone en jaque este presupuesto al otorgar voz a un asesino de mujeres en serie, a ese hombre que consideraríamos enfermo por sus actos feminicidas y que resulta ser un sujeto no tan diferente a nosotros. Al narrar los crímenes en primera persona, Poblete logra que, como lectores, espectadores, incluso confidentes, nos cuestionemos si ese sujeto que es capaz de asesinar dista tanto de quien no asesina, si ese asesino de mujeres puede considerarse enfermo o es un vecino cualquiera, de quien jamás dudaríamos de su estabilidad mental. La novela debate acerca de lo que entendemos por normalidad y civilidad, o locura y bestialidad, proponiendo que estas no son más que construcciones simbólicas que permiten establecer una barrera frente a aquellos actos o actitudes que nos perturban y nos provocan miedo.

El presente artículo, por tanto, se hace cargo de la voz del criminal, de los pensamientos que permiten justificar, a sus propios ojos, los asesinatos que comete. Así, aunque existe una comunidad que insiste en catalogarlo como un anormal, predomina la consciencia de su narrador que se ve a sí mismo como un hombre superior, sano y estable, un ser evolucionado. Ello, sin embargo, no implica que el narrador se aleje por completo de la animalidad, tal como lúcidamente lo nota Francisco Leal, sino que la entiende como un signo de supremacía, una evolución de las especies en el sentido darwiniano. Esta apropiación de rasgos animales, lejos de permitir circunscribir al asesino al ámbito de la anormalidad o enfermedad, da cuenta de una imitación racional estudiada que le otorga, además, la capacidad de enmascararse como un trabajador serio para ocultar sus crímenes. Esta racionalidad misógina, que es producto no de la anormalidad o de una conducta animal, sino de una masculinidad precaria, es la que intentaremos desentrañar a lo largo del presente artículo, abriendo con ello un debate que se actualiza cada vez que un periódico titula que una mujer más ha sido asesinada por la locura amorosa de un hombre o la bestialidad de un agresor.

\section{LA OTREDAD DE UN ASESINO}

La otredad ha sido estudiada por múltiples teóricos desde diversos enfoques metodológicos. Claude Leví-Strauss fue uno de los pioneros en este debate al remontarse a las comunidades preclásicas y darle un nombre a la dicotomía: civilización versus barbarie. En su libro Antropología estructural (1992), basado en una investigación antropológica, propuso que en el mundo griego, el hombre para considerarse parte de la comunidad, debía cumplir ciertas condiciones impuestas en base a la semejanza entre los pares. Quienes no cumplieran con dichos parámetros (lingüísticos, físicos, geográficos, mentales, de costumbres y prácticas) podían ser discriminados, marginados, borrados del mundo de los humanos por su diferencia. De esta forma, se estableció la oposición entre aquellos que pertenecían a la civilización de aquellos considerados bárbaros ${ }^{2}$.

En adelante, $N M I$.

Los bárbaros para los griegos, eran aquellos que no hablaban su lengua; como no podían entenderlos se los ignoraba o se los encerraba, los bárbaros debían ser aleccionados para entrar en la comunidad o eliminados por no compartir el código (Cfr. Levi-Strauss 1992). 
Michel Foucault en un curso dictado en el Collège de France, también abordó esta paradoja, esta vez, bajo el concepto de lo anormal: desde aquellos seres incapacitados físicamente, vistos por otros como monstruos, hasta el criminal entendido como un monstruo moral. En su investigación acerca de la historia de la psiquiatría y su vínculo con las leyes, Foucault propone que es en el siglo XIX que comienza la sospecha sistemática de la existencia de una monstruosidad en el fondo de toda criminalidad, una monstruosidad que se relaciona con la bestialidad y a la naturaleza salvaje, por cuanto, todo criminal es un sujeto que desconoce e infringe los pactos sociales: "¿no vamos a vernos ante un individuo de naturaleza que trae consigo al viejo hombre de los bosques, portador de todo ese arcaísmo fundamental anterior a la sociedad, y que será al mismo tiempo un individuo contra la naturaleza? En resumen, ¿el criminal no es precisamente la naturaleza contra natura? ¿No es el monstruo?” (Foucault 2000: 91).

Tal como ocurría con los bárbaros, percibidos como animales en contraposición a los civilizados, los criminales, los monstruos morales según los términos de Foucault, son también animalizados, sujetos otros, diferentes, por cuanto se han alejado de lo establecido, se han desvinculado de los lazos que sostienen a la comunidad. Los periódicos y los abogados, muchas veces reproducen este juicio ${ }^{3}$, así como la crítica que se ha hecho de la novela rescata de igual modo la animalidad del personaje feminicida. Francisco Leal, por ejemplo, en su reseña "Algunos animales" revela la recurrencia zoológica en la narrativa de Poblete e indica que en No me ignores se hace evidente en la personalidad del criminal, quien interpreta los actos bestiales que observa en los programas educativos y hace suya la simpleza del asesinato en la naturaleza: "Lo animal se solapa con el protagonista. Pero su bestialidad se encubre con normativas o coartadas sociales: mujer, hijos, trabajo, proyectos" (Leal 2010). Diamela Eltit, por su parte, en la contraportada del libro lleva esta animalidad, descrita por Leal, al terreno de la enfermedad mental: "Un asesino serial que cita el encuentro ya clásico entre sangre, enfermedad y sexo en medio de las manías ultra bizarras y absolutamente dementes de un sujeto que se niega a aceptar su insignificancia", afirmación que remite a la irracionalidad adjudicada tradicionalmente a los animales quienes, sin embargo, no cuestionan su insignificancia en su lucha por sobrevivir de las garras de otros depredadores. En la misma línea, Patricia Espinosa lo define como un psicópata, indiferente a la trascendencia de sus acciones: "un tipo inmune al dolor que provoca y a su vez muy racional para ejecutar con obsesivo detallismo cada uno de sus planes. El personaje se esmera en mover las piezas de su criminal juego, adoptando una pose de provinciano trabajador, introvertido y hasta gentil para seducir a sus víctimas" (Espinosa 2010). Irracionalidad y racionalidad confluyen en estas descripciones, puesto que ambas refuerzan la idea de la animalidad y demencia con que actúa, mientras ellas mismas lo dotan de humanidad: Eltit al adjudicarle un sentimiento de insignificancia y Espinosa al referir la máscara con la que engaña a sus pares y el meticuloso procedimiento que realiza para llevar a cabo sus asesinatos y permanecer impune. ¿No resulta contradictorio, entonces, afirmar que un animal es capaz de razonar?

El 21 de mayo del 2015 el diario chileno La Cuarta titulaba "Bestia asesinó a mujer y sus dos pequeñas hija en La Florida”. En septiembre del 2015, Luis Reyes Fuentes, el médico que asesinó a su mujer en Huechuraba declaraba para el matinal de Chilevisión que cometió el crimen en un momento irracional e instintivo. En abril del 2016 Marco Antonio Olmos fue puesto en libertad vigilada luego de acuchillar a su esposa, ya que su defensa argumentó que actuó bajo un estado emocional alterado. 
Esta idea común de que un asesino es un sujeto enfermo, animal, anormal, se cuestiona en la novela cuando es el asesino quien habla. Toda la narración se detalla en primera persona, por lo tanto, como lectores podemos escuchar a este hombre que tradicionalmente circunscribiríamos al ámbito de la bestialidad y comprender dos cosas: la primera, que racionalmente no se encuentra tan lejos de nosotros, que no es un monstruo que pudiéramos reconocer a simple vista cuando se camufla en la sociedad; la segunda, que es él quien ve al resto de los humanos como seres inferiores, bobalicones e irracionales, naturaleza pura, mientras él se define a sí mismo como un ser evolucionado, todo ello para ocultar una masculinidad precaria.

\section{LA RACIONALIDAD DEL ASESINO}

Aunque es innegable que el feminicida de Poblete tiene inclinación hacia lo animal, como ha referido Leal, esta relación con el mundo zoológico proviene de una admiración: admiración a sus actos de supervivencia, a su instinto y la supremacía de unos sobre otros ${ }^{4}$. Así como admira a los leones y los tigres repele a las criaturas pequeñas como cucarachas, ratones, e incluso, gatos y perros, a los cuales no atribuye rasgos de superioridad frente a otras especies. El asesino se identifica con los reyes de la selva y busca imitar algunos de sus atributos, no obstante, siempre establece la diferencia entre ellos y él, entre el instinto y la inteligencia, recalcando su posición de hombre evolucionado en contraposición a las bestias y a los otros hombres. Se erige, con ello, en el rey de su propia sabana que es la sociedad.

Una de las características de la naturaleza que resalta es la procreación, un tema que lo obsesiona y que a pesar de aunarlo, en cierta forma, con la conducta animal, lo hace diferenciarse como ser humano. Aunque, como señala Leal, practica una sexualidad mayormente anal, tiene plena conciencia de que el sexo vaginal debe reservarlo para procrear. Asimismo, establece la diferencia entre tener hijos para perpetuar los genes, de la crianza y el cuidado. Los animales, argumenta, saben por instinto que deben dejar descendientes "Entonces lo mínimo que puede hacer el hombre es superar eso, aprender de eso y proponer algo mejor. No ser mediocre, porque el mediocre sólo aspira a imitar, nada más, nada original y ningún esfuerzo extra" $(N M I: 174)^{5}$.

Entiende que las particularidades de la vida animal también son parte de su humanidad y las adopta y transforma para su beneficio. El hombre, según lo entiende, se diferencia de las bestias gracias a su inteligencia, de esta forma, puede satisfacer sus deseos usando su razón y no simplemente su instinto. Y así lo lleva a cabo, por ejemplo, en el momento en que su padre descubre su caja fuerte en la que guarda partes desmembradas del cuerpo de sus víctimas y piensa en matarlo como lo haría

\footnotetext{
Admiración hacia el reino animal que no difiere mucho de la imagen tradicional de macho, en palabras de Monsiváis: "Hombres en la acepción zoológica de la palabra, es decir, un macho que disfruta de toda la potencia animal" (Monsiváis 2013: 54).

5 La mediocridad como condición humana fue tratada en extenso por el argentino José Ingenieros en su texto $E l$ hombre mediocre. Para él un hombre mediocre sería un sujeto promedio, domesticado por la sociedad y pasivo, acostumbrado a imitar al resto, exactamente la misma concepción que parece tener nuestro protagonista acerca de sus pares. El narrador se definiría como un hombre superior, según la idea de Ingenieros, por cuanto "Es original e imaginativo, desadaptándose del medio social en la medida de su propia variación” (Ingenieros 2000: 39).
} 
un animal que se siente acorralado, ya que: "estaría protegiéndome a mí mismo, como cualquier animal que sabe que tiene que sobrevivir si otro te amenaza, es instinto, es natural" (NMI: 157). Sin embargo no lo asesina. Su condición humana, en cambio, lo ayuda a mentir, a manipular la situación de tal manera que su padre termina por dejarlo en paz.

A pesar de que él se sabe diferente a los animales en el uso de su voluntad e inteligencia, el discurso social intenta circunscribirlo en el terreno de la irracionalidad. Luego del asesinato de los padres de su novia es catalogado como un enfermo, un hombre que porta traumas de la infancia, producto de problemas con sus progenitores e incluso se especula que pudo haber sido abusado sexualmente cuando niño. Junto a ello, los psicólogos señalan que podría haber actuado bajo los efectos de alguna droga o que sufre un desorden de personalidad esquizotípico, una psicosis borderline. Reflexiones de las que el asesino se burla y contradice pero que, inteligentemente, acata puesto que entiende que son su pasaporte de salida y perdón.

El abogado, la tele o las personas de la cárcel, para el caso da lo mismo, diciendo que la gente piensa que lo insano (la locura) es un término psicológico, pero en realidad es legal. Significa la falta de responsabilidad de los actos propios en el momento del crimen, debido a un defecto o enfermedad mental, que aminora el intento criminal [...] Estupideces que, sin embargo, me ayudaron (NMI: 56).

El narrador, de esta forma, acepta ser considerado un enfermo -aunque le parece humillante ser llamado así- puesto que entiende que este diagnóstico lo liberará de prisión, tal como efectivamente ocurre. Al ser analizada su conducta como una rabia situacional y no un asesinato a sangre fría, así como descrito como un enfermo sin conciencia de sus actos, es puesto en libertad a los pocos días. El asesino se ríe del sistema judicial y de todas las teorías que lo eximen de culpas y lo dejan volver a cometer sus crímenes en absoluta impunidad. Su supuesta locura es la que lo salva de la cárcel y ampara sus delitos.

Inteligente, racional, consciente, a pesar del discurso psiquiátrico que lo sitúa en la orilla de lo anormal. El protagonista asesino, el psicópata, no actúa por instinto, sino mediante un método calculado. No es irracional, sino un hombre que ha estudiado castellano dos años, que sabe de mecánica y entiende cómo comportarse delante del resto, qué hacer, qué decir, cómo mirar, cuándo encontrar el momento propicio. La señora Eulalia, la dueña de la pensión donde habita, lo considera un hombre educado, trabajador, lo aprecia. Alberto Quiroz, el jefe del taller mecánico también le otorga su confianza: "Yo te veo bien a ti, te veo humilde, educado. Me he fijado que no miras a los ojos, desafiando, desafiándome. Eres modesto" (NMI: 13). Su agudeza le permite crearse una máscara de hombre normal y burlar a todos quienes lo rodean, como indica Constanza Carmi: "Ese asesino que describe en No me ignores es el mismo que te saluda cada mañana al llegar a tu trabajo o el que se sientan al lado tuyo en el metro. Esos que nunca creeríamos psicópatas" (Carmi 2010) ${ }^{6}$.

Resulta interesante señalar que Gastón Soublette en su texto "Cultura y civilización" cuestiona que en nuestro tiempo exista una normalidad, tanto en nuestro ambiente como en las personas, indicando que: "La grave alteración del sistema nervioso de la especie humana es una reacción inequívoca de la vida que nos está mostrando el término de la normalidad en el mundo. Hoy el hombre medio es un neurótico declarado, consume 'normalmente' tranquilizantes y somníferos y frecuenta a neurólogos, psiquiatras y psicólogos" (Soublette 1978: 143). Por ello, la línea entre un hombre normal y un enfermo cada día sería más difusa. 
La máscara como mecanismo fue analizado por el psiquiatra Carl Jung, quien lo asoció a una conducta racional, propia de los hombres en colectivos ${ }^{7}$. Máscara, para Jung, era sinónimo de persona, referida en su concepción antigua a la careta que utilizaban los actores teatrales griegos. Así entiende este término como una actitud externa, un complejo funcional que surge por razones de comodidad con el fin de adaptarse a las diversas circunstancias: "Mediante su identificación más o menos completa con la actitud adoptada en cada caso engaña cuando menos a los demás, y a menudo se engaña también a sí mismo, en lo que respecta a su carácter real; se pone una máscara, de la que sabe que corresponde, de un lado, a sus intenciones, $\mathrm{y}$, de otro, a las exigencias y opiniones de su ambiente" (Jung 1994: 492-493). Gracias a este mecanismo los hombres pueden camuflarse y adecuarse a los otros, perderse en una aparente normalidad ${ }^{8}$. Artificio que el feminicida comprende a la perfección, valiéndose de él para cubrir su verdadero rostro.

Pero su inteligencia no se reduce a la apropiación y utilización de esta máscara de vecino común. También se revela en sus planes, sus elecciones, sus métodos calculados que le proveen la seguridad para actuar en la impunidad. Por ejemplo, tiene perfecta conciencia de los instrumentos adecuados para llevar a cabo sus crímenes. Sabe que una pistola lo delataría fácilmente por el ruido, en cambio, un cuchillo o sus propias manos le garantizan mayor silencio y, por ello, un mejor resultado. Asimismo, es capaz de tomar precauciones que facilitan su tarea y evitan errores, entre ellas, quitar la luz de su auto, buscar un lugar determinado de antemano para deshacerse del cuerpo, tener la fosa semi cavada y emplear la bolsa plástica que cubren los colchones o las de máquinas de gimnasio: "una muestra de inteligencia, una muestra de saber adaptarse y de ver dónde se encuentran las posibilidades, por más raras que parezcan, en eso consiste, en la inventiva y en el ingenio" (NMI: 80).

Del halcón, que puede permanecer horas vigilando a una presa y esperando la oportunidad precisa, toma el ejemplo y lo adapta a sus fines. Espera la oportunidad y es precavido, lo que le garantiza cumplir sus objetivos sin ser descubierto. Aunque aclara que en Talca era más fácil asesinar y deshacerse de los cuerpos, el tener mayores obstáculos y correr mayores peligros lo seduce, puesto que implica, también, un mayor desafío intelectual: "más desafío, sutileza, recompensa, lo cual indica un paso adelante, como un paso adelante en la historia del hombre y por lo tanto de la evolución del hombre como raza. Mientras más pruebas, más trabas y mayor necesidad de actuar a partir de esas complicaciones; mientras más problemas, mayor desarrollo de la inteligencia y de la capacidad de sobrevivir" (NMI: 79).

Este hombre, que sería considerado un animal irracional o un demente, por su actuar criminal, demuestra su inteligencia en las precauciones y los métodos que emplea para asesinar impunemente. Este ser que tradicionalmente sería tachado de inhumano y desalmado, no obstante, presenta una capacidad de cariño y empatía, sino con todos, al menos con la señora Eulalia, a quien protege y acompaña. Así como asegura haber amado a su madre, la dueña de la pensión representa para él la

Jung llama colectivos a "todos aquellos contenidos psíquicos que son peculiares no de un individuo, sino de muchos individuos a la vez, esto es, de una sociedad, de un pueblo o de la humanidad" (Jung 1994: 499).

8 Romeo César asegura que las interpretaciones dadas por Nietzsche apuntan a la máscara como un "disfraz o mascarada mendaz del hombre civilizado [...] o como artificio para ocultarse que nace de la inseguridad; o como arma contra los otros" (César 2012: 135). El ocultamiento del rostro de quien la porta como un mecanismo para no ser reconocido. 
posibilidad de reivindicar el daño que le causó a su progenitora al alejarse de ella. Por ello, la considera como una madre. Si bien, en un momento de odio piensa en asesinarla se arrepiente de inmediato y declara que siente ganas de llorar por tan solo haber imaginado que podría llegar a matarla.

El sentimiento de culpa que expresa por haber pensado siquiera en la posibilidad de dañar a la señora Eulalia, en cambio, parece no poseerlo al acabar con sus víctimas. La culpabilidad, para el narrador, es un invento, algo que nos enseñan desde niños y que sólo algunos aprenden ${ }^{9}$. Los animales, al contario, actúan por instinto. Así, al observar un programa educativo en el que un león mata a dos leonas y luego a sus crías, reflexiona que el reino animal mata "sin ningún problema y sin ningún cargo de conciencia porque eso es algo que sólo el hombre siente, y ni siquiera todos, eso es algo artificial que nos enseñan desde chicos" $(N M I: 105)^{10}$.

Un hombre inteligente, precavido y reflexivo, difícilmente puede ser asociado a la barbarie o la monstruosidad, a pesar de la relación que él mismo indica tener con los animales, al tomar de ellos ciertos atributos que le sirven para sus propósitos asesinos: la paciencia del halcón o la superioridad física del león. Él, no obstante, se considera superior a las bestias por cuanto ha evolucionado, así como se siente superior a los otros hombres que lo rodean, más inteligente que los otros mecánicos del taller, más alto que su propio jefe, privilegiado frente a casi todos los chilenos con ascendencia mapuche. Él se ve a sí mismo como parte de la civilización, en contraste con los que lo rodean: los mapuchitos, indigenas, animalitos. Esos que:

queman y queman, son destructivos y ni siquiera su propio ambiente, su propio hábitat han sido capaces de conservar. No han aportado nada, ninguna tecnología, como los europeos, por ejemplo. Si no fuera por los europeos seguiríamos viviendo en rucas; quiero decir, ellos seguirían, porque yo soy cien por ciento caucásico y esa es la diferencia, esa es la diferencia fundamental [...] Nunca he entendido de qué se quejan si ni siquiera han podido defender sus tierras, que es lo que cualquier animal hace en su terreno (179).

La otredad se personifica en esta etnia que él ve ajena, diferente, incluso peor que cualquier animal. Un odio hacia lo que se considera inferior y se vuelve susceptible de circunscribir en el terreno de lo salvaje y violento, producto de la extensa guerra que lidiaron con los conquistadores y que llevó a sustituir el mito del "heroico araucano" por el nuevo estereotipo de barbarie que perdura hasta nuestros días y que ha sido ampliamente estudiado por José Bengoa:

Franz Kafka compartía la idea de que el sentimiento de culpa era una invención que la sociedad introyectaba en los individuos para dominar sus conductas. Él lo denomina mala conciencia: "La mala conciencia es tanto la conciencia de culpa como la confesión que el individuo se hace a sí mismo de su propia esterilidad "inherente". Pero esta confesión no le viene ex nihilo, sino como parte del programa de sujeción del sistema dominante. La mala conciencia no es sino el punto de llegada de la represión, a saber, la sustitución de la represión visible por la autorrepresión de la conciencia" (Hopenhayn 1983: 16).

10 Freud, en su libro El malestar en la cultura, también refiere a la culpabilidad como el problema más importante de la evolución cultural, señalando que el precio pagado por el progreso reside en la pérdida de felicidad por el aumento del sentimiento de culpabilidad: "El super-yo es una instancia psíquica inferida por nosotros; la conciencia es una de las funciones que le atribuimos, junto a otras; está destinada a vigilar los actos y las intenciones del yo, juzgándolos y ejerciendo una actividad censoria. El sentimiento de culpabilidad -la severidad del super-yo- equivale, pues, al rigor de la conciencia; es la percepción que tiene el yo de esta vigilancia que se le impone" (Freud 2002: 77). 
La primera experiencia del encuentro con los heroicos antepasados es traumática; están en el bando contrario, y se comportan salvajemente, para la mirada chilena criolla. Surge el estereotipo: son bárbaros, son salvajes; sus costumbres son degradantes, son borrachos y nos les gusta el trabajo; para la guerra no son tan valientes como crueles. Llegará el momento en que el país santiaguino, civilizado, culto, gritará unánimemente: ¡Acabad con ellos! Y el estereotipo se mantendrá hasta hoy: flojos, borrachos, lentos y lerdos (Bengoa 2000: 151) ${ }^{11}$.

Esta supremacía frente a los mapuches considerados como salvajes, se evidencia también al referirse a los jóvenes ricos que le compran droga -a quienes tilda de maricones-, a los homosexuales y, especialmente, a las mujeres. Una hegemonía que se basa en el concepto de evolución y se relaciona con los principios de Darwin (1859), quien hablaba de una selección natural considerando que, producto del excesivo incremento de la población, los recursos, el espacio y los alimentos cada vez serían más reducidos. En esta competencia entre hombres sólo los más aptos sobrevivirían a las catástrofes naturales y humanas. La supervivencia del más fuerte, tal como lo expresa respecto a su hermano mayor que ha muerto: "Parado aquí en lugar de mi hermano muerto. Claro que sí, lo reconozco, por lo tanto, soy mejor, soy más evolucionado, como es el destino de la especie" (NMI: 74). Un hecho que considera una prueba más de su superioridad frente a su hermano y a todos a los que tiene la facultad de asesinar.

Tras esta aparente seguridad y superioridad, sin embargo, se esconde un varón en precario ${ }^{12}$. Un hombre inseguro de sí mismo, atormentado por las marcas de acné de su rostro, por un tatuaje y un pasado que no puede borrar por más asesinatos que cometa. Un hombre que necesita auto-convencerse de que ejerce algún tipo de poder sobre los otros, que porta alguna hegemonía, aunque sea a través de la fuerza física y la inteligencia que utiliza para cometer sus crímenes. Él necesita demostrarse a sí mismo y a sus pares masculinos que merece estar vivo en el lugar de su hermano, que su existencia tiene una finalidad original, creativa.

A esta insignificancia es la que se refiere Diamela Eltit en la contraportada de la novela y que Nicolás Poblete describe: "es una forma de pedir, de gritar, de ser considerado, precisamente por las limitaciones afectivas que carga este personaje, por su increíble falta de amor propio, y por su insignificancia", le dice el escritor a Constanza Carmi (2010), así como le revela también a Paola Mosso: "El grito de este asesino es que lo tomen en cuenta, que no lo pasen por alto, que el entorno capte que tiene algún poder: el poder de abusar de otros" (Mosso 2010). Por ello, la importancia de que el personaje carezca de nombre, símil de una falta de identidad, de una sensación de abandono, de estar perdido, como argumenta el escritor en la entrevista realizada por Paola Mosso para el diario "La Nación".

Su obsesión por verse en la televisión, en uno de esos programas criminológicos con perspectiva histórica que observa con la señora Eulalia, es la confirmación de

Este sentir respecto a la inferioridad del pueblo mapuche parece ser una constante en Chile. En el año 2013, la pintora Carmen Aldunate opinó en su cuenta virtual que los mapuches eran "asesinos, cobardes, flojos y ladrones; además de borrachos y aprovechadores".

12 En una lectura psicoanalítica, siguiendo el pensamiento de Alfred Adler y Carl Jung, esta supuesta seguridad y superioridad del narrador asesino, encubriría el sentimiento de inferioridad de un neurótico que busca una compensación, es decir, que establece una ficción que contrapesa la inferioridad: "La ficción o 'línea directiva ficticia' es un sistema psicológico que intenta transformar la inferioridad en superioridad" (Jung 1994: 501). 
su deseo de trascendencia, de fama: "de una persona cualquiera, o sea una persona de cierta importancia, de cierta relevancia histórica podríamos pasar, perfectamente podríamos pasar a mí ¿verdad? Podría ser algo parecido a la fama, la compensación y el privilegio dentro de la pantalla" (NMI: 21). Un propósito de inmortalidad que se refleja en sus crímenes, así como en su aspiración por ser padre. La esperanza de dotar de sentido a una vida vacía, robada, en cierta forma, a su hermano muerto y que debe justificarse ante los ojos de sus padres y de la sociedad completa.

\section{Misoginia: "ELIminar toda esa RazA"}

Así como se tiende a catalogar a los homicidas como otros, bárbaros, enfermos o animales, este feminicida hace lo mismo. Él busca sentirse superior al resto de la humanidad, más evolucionado, más fuerte, soberano y poderoso, con el fin de paliar una inseguridad adquirida y, para ello, cataloga a sus pares masculinos como maricones y a las mujeres como esclavas o prostitutas. De cualquier manera, razas diferentes, inferiores, subalternas que deben ser castigadas, controladas o eliminadas. De ser el feminicida la bestia que necesita ser vigilada y coaccionada, son las mujeres y los homosexuales a quienes el criminal asocia con la naturaleza que debe ser civilizada.

Aunque ya desde el primer momento el narrador se pretende superior a otros hombres, como los mapuches o sus mismos compañeros del taller de mecánica, es a un homosexual a quien asesina. Calificándolo de "fleto" y "maraco", decide que un ser como él no debe vivir, puesto que porta una debilidad inherente producto de su condición sexual: "mi oportunidad de enseñarle algo a esta mierda de ser humano, como todos sabemos, mierda que debe ser evacuada tal como al tirar la cadena, o sea, basura humana que jamás debió haber nacido" (NMI: 119). Acorde a su concepción de supervivencia del más fuerte, supone que, por presentar características femeninas en su actuar, es un ser frágil que no merece haber nacido ${ }^{13}$.

Asesinar a homosexuales también podría ser considerado una especie de feminicidio, por cuanto es un crimen de odio ${ }^{14}$ en el que se intenta eliminar de ellos precisamente esa conducta asociada a lo femenino ${ }^{15}$. La base de este tipo de homicidio es, como en el caso de los asesinatos contra mujeres, el machismo y la masculinidad hegemónica que ve en los homosexuales una desviación de la regla básica: ser un hombre significa no ser como las mujeres (Kimmel 1997). De esta forma los hombres homosexuales, producto de su orientación sexual y su asociación con lo femenino,

Este rechazo hacia lo femenino fue resumido por Robert Brannon como uno de los principios de la virilidad: "¡Nada con asuntos de mujeres!" Uno no debe hacer nunca algo que remotamente sugiera femineidad. La masculinidad es el repudio implacable de lo femenino" (citado en Kimmel 1997). De ahí el rechazo y odio hacia lo masculino feminizado en relación también a las mismas mujeres vistas como seres inferiores.

14 "Los crímenes de odio se dirigen contra una persona y lo que simboliza, representa y encarna, y son, en este sentido, acciones de furia contra la especie. Los victimarios no conocen previamente a la víctima, y al liquidarla se sienten en posesión de ese poder sin límite, el exterminio del mal (en el vocabulario homicida el mal es el comportamiento detestado y es la debilidad física y social de la víctima)" (Monsiváis 2013: 171).

15 Mujeres transgénero mexicanas, desde hace muchos años, piden a representantes del Tribunal Permanente de los Pueblos (TPP) que se pronuncien para que los homicidios cometidos hacia este grupo sean clasificados como feminicidios en dicho país. http://pulsoslp.com.mx/2014/08/06/mujeres-transgenero-en-mexico-buscan-quecrimenes-en-su-contra-sean-feminicidios/ 
pasan a ser considerados masculinidades subordinadas y son blanco de experiencias que van desde la exclusión hasta la violencia verbal y física: "La opresión ubica las masculinidades homosexuales en la parte más baja de una jerarquía de género entre los hombres. La homosexualidad, en la ideología patriarcal, es la bodega de todo lo que es simbólicamente expelido de la masculinidad hegemónica" (Connell 1997: 40).

La violencia contra los homosexuales, así, se convierte en una manera de exigir una masculinidad en el otro y afirmar la propia, según el decir de Connell, a la vez que se ampara en el contexto de una sociedad patriarcal que reproduce esta visión. Por esta razón, el narrador al momento de asesinar al homosexual pareciera sentir que está ejerciendo un derecho, su actuar no necesita más justificación que el hecho de estar eliminando a un ser inservible, enfermo, anti natural y desviado. La impunidad en la que permanece su muerte reafirma la poca validez que se le imprime a la vida de un hombre afeminado ${ }^{16}$.

Luego de este episodio en que asesina a un homosexual, el protagonista seguirá con su objetivo principal: exterminar a las mujeres, a quienes considera inferiores, seres creados para obedecer, acatar y satisfacer los deseos sexuales y las pulsiones violentas. Las define como: "chica/maraca/putilla (tantos nombres para la misma mierda)" (NMI: 87). Apelativos que denotan una infantilización y asociación de todas las mujeres con prostitutas. Prostitutas que gozan de la violencia que se ejerce contra ellas, prostitutas que deben entregarse sexualmente a cualquiera que se lo exija y que deben soportar su castigo y aleccionamiento cuando se resisten. Prostitutas cuya muerte pasará desapercibida.

Prostitutas, cucarachas, enfermas mentales, seres animalizados a quienes hay que eliminar o ayudar a morir: "Siempre hay que tener en cuenta lo que se llama 'misericordia' hacia esta mujer que sufría una enfermedad mental, cualquiera se hubiera dado cuenta, y necesitaba a alguien que la ayudara a morir" (NMI: 27). A la par de identificar a sus víctimas como enfermas mentales, en otras ocasiones las asocia con insectos, alimañas que deben ser aplastadas: "cucaracha fuerte, difícil de aplastar y que aguanta y corre, pero que finalmente yo piso y piso; aplasto la asquerosidad negra y que vive como cualquier otro ser vivo, que quiere vivir pero que es necesario eliminar, idealmente eliminar toda esa raza o especie. Eliminarla como lo que son, aplastarlas por lo que son" (NMI: 92).

Coherente con su posición de varón en precario, define a las mujeres que asesina como sujetos con un comportamiento incorrecto y desviado: deshumanizadas, malvadas, perversas, que necesitan aprender a circunscribirse a los parámetros de su hegemonía. Para el asesino no son víctimas, como intentan hacer creer los diarios o los libros de criminología, son culpables de su destino. Responsables de lo que les ocurre porque han osado desafiar la autoridad del feminicida, mirarlo en menos, no consentir a la incitación sexual. Así, el narrador se asume como un héroe, un ser superior y evolucionado cuya misión en el mundo es aleccionar a aquellas insumisas, castigarlas, corregir su actuar, educarlas, enseñarles el respeto:

6 Hasta hace muy poco tiempo, en Chile la violencia y el asesinato de homosexuales era escasamente investigado y, menos aún, penado. Fue recién en el año 2012 que se promulgó la Ley Antidiscriminación, bautizada con el nombre de Daniel Zamudio, luego de que varios individuos golpearan hasta matar al joven del mismo nombre producto de su orientación sexual. La Ley actual busca frenar todo tipo de discriminación arbitraria, siendo la violencia contra los homosexuales duramente castigada. 
Una secretaria, una putilla, todo el mundo lo sabe. Pero qué tetas, qué culo, y siempre ignorándome, siempre haciéndose la cuica [...], pero ya vas a ver a quién le vas a pedir perdón, a quién vas a pedirle disculpas y manifestar tu respeto, reconocer $m i$ superioridad. A quién le va a importar, siempre desaparece alguien, alguna mierda humana que a nadie le interesa, una mierda que ni siquiera debería haber nacido (NMI: 148).

Ignorarlo se constituye en el motivo suficiente para el asesinato. Lo mismo ocurre con meseras de bares a quienes culpa por la indiferencia en el trato o por mirarle las marcas de acné ${ }^{17}$. A pesar de su insistencia en una supremacía inexistente es un hombre inseguro que debe demostrar su poder a golpes, asesinando. Repitiéndose de manera constante que las mujeres no son más que putas, presas fáciles, fáciles de complacer y de llevar a la cama: "porque nadie me pone el pie encima a mí, y la puta, tarde o temprano, sabe quién es el que manda y quién es el jefe aquí" (NMI: 115). El feminicidio se transforma en castigo, en aleccionamiento, pero, a la vez, se constituye en una muestra de poder y autoafirmación de una masculinidad precaria, por ello no le resulta suficiente el asesinato sin violación previa.

El asesino presenta el cúlmine de su satisfacción sexual en la emergencia de la sangre y los gritos de la víctima. El orgasmo coincide con la expiración. Y esta adicción por una sexualidad agresiva no sólo se manifiesta con sus presas, tal como las llama, sino también con sus parejas sentimentales que aprueban esta violencia y contribuyen a perpetuar esta cadena de dominación en la que ellas son las oprimidas ${ }^{18}$. En las relaciones sexuales con Doris, por ejemplo, el cuchillo se transforma en un símil del falo, así como en un instrumento de tortura psicológica: "Presiono la hoja en la oreja, ¿a ver cómo se ve esa orejita en un frasquito', susurro y Doris gime algo y ahora sí que tengo el pico parado" (NMI: 47). De la misma manera, el asesino concluye que todas las mujeres disfrutan de la violencia y los golpes: "era la típica mina que igual se calienta cuando le pegan" (NMI: 110).

Violencia y erotismo se combinan para satisfacer sus deseos, sin embargo, la agresión no cumple solamente el rol de proporcionar placer sexual sino también de otorgarle esa seguridad en sí mismo de la que carece. Soberano, es como se define después de violar a una joven. No temeroso ni arrepentido sino soberano, con el control en sus manos ${ }^{19}$. El feminicida requiere de una presa para sentirse poderoso y validarse como hombre. Por ello también la necesidad de pequeños trofeos que perpetúen su hegemonía. Recuerdos que primero son partes del cuerpo de las mujeres asesinadas, un diente de oro convertido en una bolita, y luego devienen en fotografías, cintas de video filmadas durante la tortura. Una prueba de su dominio.

Una conducta idéntica a la del asesino en serie estadounidense David Berkowitz, quien declaró que "Tenía la determinación y estaba en total acuerdo conmigo mismo de que debía asesinar a una mujer con propósitos de venganza y para humillarlas por todo el sufrimiento que me causaron" (Russell 2006: 346)

18 Concordante con la idea de dominación masculina: "Si la relación sexual aparece como una relación social de dominación es porque se constituye a través del principio de división fundamental entre lo masculino, activo, y lo femenino, pasivo, y ese principio crea, organiza, expresa y dirige el deseo, el deseo masculino como deseo de posesión, como dominación erótica, y el deseo femenino como deseo de la dominación masculina, como subordinación erotizada, o incluso, en su límite, reconocimiento erotizado de la dominación” (Bourdieu 2007: 35).

19 Monsiváis explica el acto de la violación justamente como una afirmación del Yo o como un desquite: "Educados en un penoso culto a la "hombría", convencidos sinceramente de que la mujer sólo eso desea, incapacitados para recibir crítica alguna o para enfrentarse verdaderamente a sus explotadores, abrumados por sus dificultades, muchos recurren a la violación como el supremo acto de afirmación del Yo o como el desquite" (Monsiváis 2013: 67). 


\section{Doris, LA FEMINICIDA CÓMPLICE}

El asesino sin nombre no siempre actúa solo. En su trayectoria conoce a Doris, la mujer que se convierte en su compañera sexual y en otra feminicida cómplice de este representante del patriarcado. Doris, a pesar de ser una joven que se supone educada, puesto que ha sido profesora de historia, sí pareciera sobrevivir por instinto y no por una inteligencia o racionalidad, a diferencia del criminal. Ello se demuestra, por ejemplo, en su primer delito: al salvar su vida, de manera inconsciente, utilizando a una compañera de trabajo como escudo para esquivar una bala. Instinto de supervivencia sin culpas. Una reacción animal.

Su misma relación con el asesino pareciera obedecer a un instinto de supervivencia y protección, puesto que, como ella reconoce, toda su vida ha sido abandonada y despreciada, incluso por un hombre que la violó. Ella, a pesar de asegurar que disfrutó ser ultrajada y lo cataloga como una linda experiencia, siente que esto la marcó por el hecho de que el violador la utilizó para luego dejarla. El libro de criminología que leen diagnostica su reacción como parte de una "vulnerabilidad o indefensión aprendida", "desamparo", "síndrome de la mujer golpeada" que padecen: "algunas mujeres que permanecen con el abusador. De ahí viene la teoría de Martin Seligman sobre la 'indefensión aprendida' que explica por qué algunas mujeres no solo permanecen con su victimario, sino incluso, a veces, llegan a participar de sus crímenes" (NMI: 46). Síndrome que, como indica el narrador, se ha comprobado a través de experimentos con perros golpeados que se terminan rindiendo ante las agresiones sistemáticas ${ }^{20}$.

Una mujer que, a pesar de ser educada, termina asociada al terreno de la naturaleza y animalidad debido a su instinto de protección que la hace acudir a un macho protector y agresivo que, sin embargo, la cuida. Si bien su compañero la considera una mujer inteligente, diferente al resto, y por ello la hace parte de sus crímenes, Doris debe aprender que él es quien tiene el poder y asumir su posición de sujeto subalterno: "al final los dos supimos quién iba a ser el superior, quien iba a mandar, como en un clan de animales siempre hay uno que manda, y siempre es el macho el que manda y el que da las órdenes" (NMI: 126). Así, el feminicida la insta a firmar un contrato en el que acepta su posición de esclava a cambio del amparo que él le brinda:

Soy su posesión total. Puede hacer todo lo que quiera conmigo. Le debo total obediencia, y él puede castigarme si lo juzga necesario. Por voluntad propia firmo este contrato $y$ soy responsable de mis actos. Porque no eres tonta, porque sabes que ser la mejor esclava es la manera más eficaz de estar mejor, de no ser más despreciada, claro que sí, nunca más maltratos, nunca más desaires (NMI: 136).

Esclava del asesino porque ella lo estaba buscando, porque lo necesitaba y requería de su protección como el león que protege a su leona, indica el narrador. Esclava, porque si no lo fuera entraría en el terreno de las otras, las malvadas, las prostitutas que no aceptan su lugar en el mundo y se sublevan. Es por su condición diferente

20 A diferencia del narrador asesino, Doris sí podría ser definida y considerada un ser inferior, siguiendo el planteamiento de José Ingenieros: "El hombre inferior es un animal humano; en su mentalidad enseñoréanse las tendencias instintivas condensadas por la herencia [...] Su ineptitud para la imitación le impide adaptarse al medio social en que vive; su personalidad no se desarrolla hasta el nivel corriente, viviendo por debajo de la moral o de la cultura dominantes, y en muchos casos fuera de la legalidad" (Ingenieros 2000: 39). Doris, en contraste con el feminicida, termina por alejarse por completo de la sociedad y su único vínculo lo genera con su pareja. 
que la escoge como su compañera y cómplice: "Doris: no una puta cualquiera, como (casi) todas, no una mujer mala, como (casi) todas. Distinta" (NMI: 127). De esta forma, Doris termina por completo inserta en el ámbito de la naturaleza, domada no sólo porque su instinto es más fuerte que su racionalidad, sino porque su única misión en la tierra es procrear y perpetuar los genes del asesino.

De esta forma, mientras el asesino se caracteriza por su inteligencia, Doris es definida como un animal domesticado al que debió enseñarle respeto y sumisión, a cumplir con sus obligaciones, a no contradecir; moldearla a sus gustos para convertirla en la compañera perfecta, hecha a su medida, la futura madre de sus hijos y la carnada para atraer más fácil a sus presas. Doris, sin una voluntad clara, acata todas las órdenes de su pareja: no volver a hablar con su amiga del norte, llamar a su familia sólo una vez a la semana, comer lo que él le imponía, dejar su trabajo para dedicarse exclusivamente al cuidado de los hijos por venir ${ }^{21}$.

\section{El ANIMAL ESCAPA DE LA JAULA}

Aunque el criminal ya había sido apresado una vez, producto del asesinato de los padres y de una novia, jamás fue condenado y apenas pasó un par de días en la cárcel, tal como él mismo se burla. Durante años asesina sin problemas, sin trabas y en total impunidad. Mientras se trata de homosexuales, prostitutas, secretarias o meseras, la policía pareciera ni siquiera investigar su desaparición ${ }^{22}$. La última víctima, en cambio, se transforma en su tumba, puesto que, la justicia sí actúa cuando la desaparición ya no corresponde a una joven de escasos recursos sino a una chica del barrio alto.

Usando a unos gatos como carnada, junto al evidente embarazo de Doris que la vuelve una persona confiable, recogen a una menor de edad en el Parque Padre Hurtado, una niña de aproximadamente 16 años que estaba junto a sus amigos, también de clase alta, bebiendo y comiendo un asado. Bastante borracha y, por ello, ajena a lo que sucedía a su alrededor, alejada de sus amigos que ya estaban saliendo del recinto, la joven se encuentra en una posición vulnerable, lo que a transforma en una víctima idónea.

Junto a Doris la llevan a una cabaña. Sin embargo, el feminicida impune comete el único error durante su carrera criminal: descuida durante unos segundos a la niña, que alcanza a enviar un mensaje con su celular. No obstante, confiado en su suerte anterior y en que nadie podrá encontrarla estando tan lejos de Santiago, se droga más de lo habitual hasta el punto de perder la noción del tiempo. Los narcóticos que ha consumido no le permiten moverse con rapidez ni ver las cosas con claridad. Luego de arrancarle un ojo a su víctima, ya no sabe dónde está la niña o dónde se encuentra Doris. A lo lejos escucha las sirenas del carro policial y ve las luces rojas girando pero se siente incapaz de huir.

El asesino constantemente se jacta de su voluntad, en contraposición a Doris que en el único momento en que se supone ejerce su voluntad es cuando se declara su esclava. Para Carl Jung la voluntad "es un fenómeno psicológico que debe su existencia a la cultura y a la educación moral, pero del que carece en gran medida la mentalidad primitiva" (Jung 1994: 564); otro rasgo que permite asociar a Doris con la naturaleza.

22 Para Monsiváis la impunidad es un aliciente en este tipo de crímenes, al provocar "sensaciones de omnipotencia que se desprenden del crimen sin consecuencias penales y sociales para el criminal. No es sólo superior a los seres quebradizos, también se burla de las leyes y de la sociedad" (Monsiváis 2013: 238). 
A pesar de perder movilidad y claridad de acción su inteligencia no lo abandona: "sé que he sido inteligente porque he reservado las energías para este mismo momento. Claro que sí, hay que saber adaptarse y las cosas no siempre salen totalmente como uno querría" (NMI: 209). Sus reservas de energía las utiliza así para buscar un cuchillo y cortarse la garganta frente al espejo ${ }^{23}$. Se trata de su último espectáculo, que espera ser sensacional para quienes lo encuentren y se refieran a él como uno de los asesinos más importantes de la historia.

Patricia Espinosa considera que este final es un gran error, indicando que: "contagiado con un mal recurrente en los narradores nacionales, que tienden a convertir sus relatos en parábolas del buen vivir, el autor nos golpea con un puñetazo a mansalva: sin más nos da vuelta la historia y ahí quedamos, lamentando un desenlace tan, pero tan imbécil" (Espinosa 2010). Aunque es cierto que es un final que puede parecer moralista, como de telenovela, en que los feminicidas se suicidan cuando ya no ven salida, este final resulta coherente con la propuesta racional de la novela. El asesino, un personaje que se apropiaba de ciertas conductas animales adaptándolas y transformándolas a través de su razón, se siente atrapado y, consecuente con su actuar previo, utiliza su inteligencia hasta el final, enarbola su condición humana hasta el último momento en que decide suicidarse, un acto humano, una decisión que lo equipara con Dios y eleva su superioridad a otro escalón: decidir sobre su muerte. A la par, esta decisión puede convertirlo en el personaje histórico que soñaba lograr la trascendencia y eludir la justicia humana. El suicidio lo libra de la cárcel y lo eleva a una humanidad total ${ }^{24}$.

\section{CONClusiones}

Cuando alguien se aleja de los parámetros establecidos por la sociedad, tiende a ser circunscrito en el ámbito de la animalidad o la enfermedad. Buscamos encontrar en él una célula o un gen alterado, una marca particular que nos permita reconocer su diferencia con nosotros -los normales y civilizados, una señal de su exclusión. Los asesinos, sin embargo, no son distintos a nosotros, no pertenecen a una cultura ajena. Por el contrario, son parte de nuestra sociedad, conviven y alternan con otros a diario. Nada hay en ellos que los diferencie sustantivamente del resto de la humanidad.

El feminicida que Nicolás Poblete retrata en su novela es un sujeto más de los muchos que han sido criados en un sistema patriarcal y que, por ello, tienden a ver lo femenino como algo inferior que debe ser controlado o eliminado. Un hombre misógino y sexista que reproduce la concepción machista tradicional de las mujeres

23. El hecho de suicidarse mirándose en el espejo puede ser visto como una reafirmación final de una identidad que se manifestó siempre como precaria, ya que, tal como indica el antropólogo David Le Breton "cuanto más importancia dé una sociedad a la individualidad, más agrandará el valor del rostro [puesto que, en definitiva] la dignidad del individuo entraña la del rostro" (citado en Altuna 2009: 49). Visualizar el propio rostro impulsaría la conciencia de un yo, según Le Breton. Mirarse en el espejo en el momento de su suicidio podría significar así obtener esa dignidad e individualidad, al menos, en el momento de su muerte.

24 Filósofos como Séneca, Hume y Schopenhauer consideraban que el suicidio es un acto de libertad, la máxima expresión de la voluntad humana y, por tanto, una decisión racional que sólo puede tomar un hombre soberano acerca de su vida (Cfr. Bonete 2004). 
asociadas a lo pasivo, lo subordinado, lo débil. Un hombre homofóbico que, como muchos, desprecia a los homosexuales porque los considera desviados, así como repudia a los mapuches por ser parte de una raza diferente que piensa incivilizada, no evolucionada. Nada diferente a lo que se escucha o evidencia a diario, nada ajeno a la realidad que como sociedad vivimos.

La exclusión, la violencia, la discriminación es la norma de lo civilizado. Este hombre asesino sólo lleva al extremo esta idea al intentar eliminar de raíz lo que asume menor. Mientras la mayoría margina, el personaje de Poblete asesina, una especie de marginación excesiva pero que no se diferencia mayormente de la muerte simbólica que se le impone a las minorías a diario. Al escudriñar en la conciencia del asesino descubrimos una burla. El feminicida se ríe de las etiquetas con que buscan catalogar sus acciones criminales, se ríe de los otros hombres a quienes considera mediocres porque sólo critican sin actuar, se justifica porque él es el llamado a ser un hombre superior que extermine todo lo no evolucionado.

Tal como señala Connell "La mayoría de los hombres no ataca o acosa a las mujeres; pero los que lo hacen, difícilmente piensan que ellos son desquiciados. Muy por el contrario, en general sienten que están completamente justificados, que están ejerciendo un derecho. Se sienten autorizados por una ideología de supremacía" (1997: 44). Es el caso del asesino a quien Nicolás Poblete le da voz, un hombre que jamás se asume como un enfermo mental sino, por el contrario, alaba constantemente su salud, su valentía, su heroísmo que busca acabar, sin miedo ni reparos, con todo lo que la sociedad considera menos. Un sujeto que está seguro pasará a la historia y obtendrá fama por sus asesinatos.

El narrador, por tanto, no puede ser deslindado de la civilización y de la humanidad por su conducta destructiva, al contrario, es un sujeto partícipe de la sociedad que representa a una parte no menor de la población ${ }^{25}$. Alguien con quien podríamos entablar una conversación, alguien con quien podríamos cruzarnos en la calle, alguien a quien podríamos estar leyendo en un chat cualquiera. El mismo Nicolás Poblete le afirma a Constanza Carmi: "La novela es una especie de llamada de atención al compuesto de prejuicios que se denomina 'nuestra sociedad'. De ese modo, el asesino de esta novela es una especie de ventrílocuo que va haciendo patente todos estos prejuicios hacia gente marginada: grupos indígenas, minorías sexuales; la mujer como objeto de intercambio y cosificación pornográfica, etc.” (Carmi 2010).

El gran acierto de Nicolás Poblete es darle voz al asesino para demostrar que el feminicida no es un monstruo, no es un animal, no es un enfermo mental. Es un sujeto sano, racional y meticuloso que sabe cómo actuar amparado por una sociedad y una legislación que lo exculpa. Símil a lo que muchos años atrás postuló la filósofa Hannah Arendt, respecto a Adolf Eichmann, en su texto Eichmann en Jerusalén, cuestionando la estigmatización que lleva a pensar a los criminales como animales o seres carentes de razón. Valiéndose del juicio al teniente coronel nazi, producto del genocidio contra los judíos durante el Holocausto, descubrió que este hombre, acusado de ser uno de los responsables de una de las mayores matanzas que la historia conozca, no era un débil mental o un fanático religioso, tampoco un sádico pervertido como lo calificaron, ni un monstruo como lo denominó el fiscal a cargo

Como indica Carolina Andronie (2010), la novela postula que lo cotidiano es una fuente inagotable de violencia, discriminación y resentimiento. 
(aunque hubiera sido confortante creerlo anormal, según palabras de Arendt), sino, por el contrario, era un hombre normal: "Lo más grave, en el caso de Eichmann, era precisamente que hubo muchos hombres como él, y que estos hombres no fueron pervertidos ni sádicos, sino que fueron, y siguen siendo, terrible y terroríficamente normales" (Arendt 1999: 165).

Así, al contrario de lo que se admite, la motivación que llevó a Eichmann a cometer estos crímenes no fue una perversión personal ni un factor de locura sino una obediencia al régimen del que formaba parte. Por ello, él mismo reconoció durante el juicio no sentir culpa, puesto que creía en la buena sociedad que Hitler estaba imponiendo, creía en el sueño de una colectividad más evolucionada. No es que fuera incapaz de discernir entre el bien y el mal, sino que nunca creyó que sus actos podrían ser tachados como algo reprobable o siquiera erróneo: "No tuvo Eichmann ninguna necesidad de 'cerrar sus oídos a la voz de la conciencia', tal como se dijo en el juicio, no, no tuvo tal necesidad debido, no a que no tuviera conciencia, sino a que la conciencia hablaba con voz respetable, con la voz de la respetable sociedad que le rodeaba" (Arendt 1999: 78); esto, al igual que el feminicida que creó (o reprodujo de la vida diaria) Nicolás Poblete: un hombre misógino, común, seguro de estar exterminando una raza menos evolucionada, convencido de estar haciendo lo correcto en una sociedad patriarcal que ampara e invisibiliza gran parte de estos crímenes. Un hombre terroríficamente normal cuya misión era exterminar una raza, encontrar una "solución final" para las mujeres ${ }^{26}$.

\section{OBRAS CITADAS}

Adler, Alfred. 1965. El carácter neurótico. Buenos Aires: Paidós.

Altuna, Belén. 2009. "El individuo y sus máscaras". Ideas y valores. Revista colombiana de filosofía 140: 33-52.

Andonie, Carolina. 2010. "No me ignores (...o me acrimino)". Leermehacefeliz. Web. Consultado el 16 de octubre de 2014.

Arendt, Hannah. 1999. Eichmann en Jerusalén. Un estudio sobre la banalidad del mal. Barcelona: Lumen.

Bengoa, José. 2000. Historia del pueblo mapuche (siglo XIX y XX). Santiago de Chile: Lom.

Bonete, Enrique. 2004. ¿Libres para morir? En torno a la tánato-ética. Bilbao: Desclée De Brouwer.

Bourdieu, Pierre. 2007. La dominación masculina. Barcelona: Anagrama.

Carmi, Constanza. 2010. "La visión criminal con Nicolás Poblete". Belelu. Consultado el 16 de octubre de 2014. http://www.belelu.com/2010/08/una-cita-criminal-connicolas-poblete/

César, Romeo. 2012. "Nietzsche: metáfora, fábula, ficción II (de sueños, máscaras y fábulas)". Identidades 2.3: 129-147.

Connell, Robert.1997. "La organización social de la masculinidad". En Teresa Valdés y José Olavarría (eds). Masculinidad/es Poder y Crisis. Santiago de Chile: ISIS Internacional y Flacso, Ediciones de las Mujeres no 24. 31-48.

Darwin, Charles. 1988. El origen de las especies. Madrid: Espasa Calpe.

Espinosa, Patricia. 2010. "Un psicópata de tomo y lomo". Las Últimas Noticias. Consultado el 16 de octubre de 2014. http://www.lun.com/lunmobile//Pages/NewsDetailMobile. aspx $? \mathrm{dt}=2010-08-06 \&$ PaginaId $=46 \&$ SupplementId $=0 \&$ bodyid $=0$

26 Una comparación detallada entre el feminicidio y la "solución final" nazi ha sido realizada por Diana Russell (2006). 
Foucault, Michel. 2000. Los anormales. Buenos Aires: Fondo de Cultura Económica.

Freud, Sigmund. 2002. El malestar en la cultura. Buenos Aires: Libridot.com.

Hopenhayn, Martín. 1983. ¿Por qué Kafka? Poder, mala conciencia y literatura. Buenos Aires: Paidós.

Ingenieros, José. 2000. El hombre mediocre. Argentina: elaleph.com.

Jung, Carl. 1994. Tipos psicológicos. Barcelona: Edhasa.

Kimmel, Michael. 1997. "Homofobia, temor, vergüenza y silencio en la identidad masculina". En Teresa Valdés y José Olavarría (eds). Masculinidad/es Poder y Crisis. Santiago de Chile: ISIS Internacional y Flacso, Ediciones de las Mujeres no 24. 49-62.

Leal, Francisco. 2010. "Nicolás Poblete: algunos animales (No me ignores)". Letras en Línea. Consultado el 16 de octubre de 2014. http://www.letrasenlinea.cl/?p=1026

Lévi-Strauss, Claude. 1992. Antropología estructural. Barcelona: Paidós.

Monsiváis, Carlos. 2013. Misógino feminista. México, D.F.: Editorial Océano.

Mosso, Paola. 2010. "El criminal que camina junto a ti". La Nación. Consultado el 16 de octubre de 2014. http://www.lanacion.cl/el-criminal-que-camina-junto-a-ti/ noticias/2010-07-27/203202.html

Poblete, Nicolás. 2010. No me ignores. Santiago: Cuarto Propio.

Russell, Diana. 2006. "Feminicidio: 'La solución final' de algunos hombres para las mujeres". En Diana Russell y Roberta Harmes (eds.). Feminicidio: una perspectiva global. México: UNAM, Centro de Investigaciones Interdisciplinarias en ciencias y Humanidades. 345366.

Soublette, Gastón. 1978. “Cultura y civilización”. Revista Universitaria 1.1: 141-148. 
